\title{
Determining the Effects of Chemical Admixtures on Roller Compacted Concrete (RCC)
}

\author{
Mohammad Arif Nero ${ }^{1,}$, , Soner Haldenbilen ${ }^{2}$ \\ Transportation Department of Civil Engineering, Pamukkale University, Denizli, Turkey \\ Email address: \\ arif.nero1@yahoo.com (M. A. Nero), shaldenbilen@pau.edu.tr (S. Haldenbilen) \\ ${ }^{*}$ Corresponding author
}

\section{To cite this article:}

Mohammad Arif Nero, Soner Haldenbilen. Determining the Effects of Chemical Admixtures on Roller Compacted Concrete (RCC). American Journal of Engineering and Technology Management. Vol. 5, No. 1, 2020, pp. 27-34. doi: 10.11648/j.ajetm.20200501.14

Received: April 8, 2019; Accepted: January 31, 2020; Published: March 17, 2020

\begin{abstract}
The worldwide use and implementation of roller compacted concrete (RCC) is growing because of its good technical and economic advantages especially here in turkey. Chemical admixtures basically used for conventional concrete to increase its strength and produce a good quality concrete, and there are so many companies produce chemical admixtures for conventional concrete but only few companies produce chemical admixtures for roller compacted concrete (RCC). We were able to find the only company in turkey "Lyxor" to produce chemical admixtures for RCC; meanwhile this research aims to dictate the effectiveness of some chemical admixtures for roller compacted concrete (RCC) mixtures. We have conducted a test method to characterize some of the properties of RCC and these include the compressive strength and flexural strength with direct shear test. In this research we have used mainly 2 different types of chemical admixtures which include 3 types of superplasticizers which are Nanoment SP - Superplasticizers, Nanoment MR - Midrange Plasticizer, Nanoment HP - New Generation Superplasticizers, and the other type is Nano Aer - Air Entraining chemical admixture. We have conducted the test method by preparing 3 different RCC samples using each chemical admixture and tested them constantly within 3 and 28 days comparing them with 3 different None-admixed RCC samples which was prepared with the same procedure, and in the final we have prepared the test result table of each and every sample and the comparison chart as well. In the last part some recommendations and suggestions for the use of these chemical admixtures are mentioned.
\end{abstract}

Keywords: Roller Compacted Concrete (RCC), Compressive Strength, Flexural Strength, Superplasticizers, Water Reducer, Chemical Admixtures

\section{Introduction and Literature Review}

Transportation is an important part of history and has always played a major role in human gatherings and development of civilization. There are many types of transportations we involve in our daily life such as: Human powered transportation, Animal powered transportation, Roadways, Railways, Waterways and Airways [1]. It's been said that John Louden McAdam was the man who designed the first modern highways using inexpensive paving materials of soil and stone aggregates and he designed the roads a few feet higher than the surrounding areas to cause water to drain away from the surface [2]. It is believed that the first concrete pavement was in Bellefontaine, Ohio city of United States of America in 1894 and it's still in use and it was built by George Bartholomew. But some believe that it was first used with Portland cement in 1879 in Scotland [3]. For many years concrete recipes contained only Portland cement, coarse and aggregates, sand and water. The accidental discovery of air entraining chemical admixture showed that this admixture is able to prevent freeze thaw damages in RCC mixture and it became the first chemical admixture to be used in RCC mixtures and the way was opened for the development of other kinds of chemical materials used in RCC and marketing of so many chemical admixtures [4]. Later on, companies were found, and chemical admixture industries came into begin. To determine the benefits of chemical admixtures on RCC, researches had been done and published, here we have summarized some of them.

Chetan V. Hazaree, Halil Ceylan, Peter Taylor, Kasthurirangan Gopalakrishnan, Kejin Wang, and Fatih 
Bektas they all had conducted a research in 2013 in Iowa State University, National Concrete Pavement Technology Center regarding the use of chemical admixtures in roller compacted concrete for pavements. Their research was about the use of chemical admixtures in RCC. They've considered the workability of concrete to be set up by its cohesion, compactibility, and segregation resistance, retention of workability, water reduction and consistency. They've conducted the gyratory compaction test, vibrated slump test and direct shear test used in soil to characterize each of the above-named properties. They've tested ten mostly used chemical admixtures for RCC mixtures such as: air entraining, retarders, dry cast industry products, water reducers. They've noticed that each chemical admixture has different benefits on fresh RCC like finishability and setting behavior [5].

Y. Mohan Sai Kiran, S Krishna Rao and Y. Kishore Babuji had conducted a research in 2015 regarding the Effect of Mineral Admixture on Strength Properties of Roller Compacted Concrete. Their research was conducted on silica fume roller compacted concrete (SRCC) to evaluate the modulus of rupture or flexural strength properties, compressive strength, and split tensile strength. To prepare silica fume roller compacted concrete, they've replaced cement at different percentages such as 5\%, 7.5\% and $10 \%$ by weight of cement have been added to RCC. They've performed the test to identify workability on Fresh and hardened states of RCC. Workability tests like compaction factor test, vee-bee test and slump test were conducted. Strength tests like compression strength, split tensile strength, flexural strength at 3 Days, 7 Days and 28 Days [6].

Dr. Edel Cortez and Lynette Barna, Charles Smith with the association of Cold Regions Research and Engineering Laboratory (CRREL), U.S. Army Engineer Research and Development Center (ERDC), Hanover, New Hampshire, and Terry Peltz, Peltz Companies, Inc., Alliance, Nebraska conducted a research in September 2010. Their research was to mix roller compacted concrete (RCC) with the cold weather admixture systems (CWAS) technology to develop a new energy efficient method of winter paving that may benefit expeditionary and fixed Army installations and demonstrate this in accordance with the goals of the Installation Technology Transition Program (ITTP). They've used "corrosion-inhibiting" chemical admixture to increase strength gain and "accelerating" chemical admixture to decrease the setting time and to early strength gain after curing [7].

Cenk Karakurt and Resul Pektaş had conducted a research in bilecik şeyh edebali university in 2015 regarding the properties of roller compacted concrete produced using fly ash and ground granulated blast furnace slug (GBFS). They've carried out their test on $10 \%, 20 \%$ and $30 \%$ fly ash and GBFS replaced RCC specimens [8].

As a result, the work we have done differently than others are to use very less percentage of chemical admixtures in the RCC mixtures as shown in the table 1, to gain a better and higher compressive and flexural strength without reducing its slump ratio and workability of concrete.

\section{Materials}

To produce a good quality RCC mixture its very important to select its ingredients according to requirements of the design specifications, construction requirements of the project and considering the quality of the available materials [9]. RCC materials can be: Coarse aggregate, fine aggregate, cement materials (cement, silica fume, fly ash, etc.) water, and when needed, chemical admixtures [10].

\subsection{Chemical Admixtures}

Chemical admixtures can be found as liquid and powder form and the mixing procedure of each chemical admixture can be different according to their specifications, some might be added during batching and some after batching. Dosages used are very important for the RCC mixture and every single chemical admixture has its own qualifications and functions and it's mostly depends on several factors as: the type of admixture, desired performance, weather or environmental conditions and RCC mixture specifications [11]. While using chemical admixtures in RCC firs of all we should analyze its effectiveness according to its dosage used in RCC mixture. The selection of chemical admixture is very important for the desired specification of the project and it should be selected very carefully. In this study we have chosen 2 main kinds of chemical admixtures which are Superplasticizers and Air entraining agent, and the dosages used for the tests are shown in the table below (table 1).

1. Nanoment L24-SP - Superplasticizing Chemical Admixtures.

2. Nanoment L23-MR - Midrange Plasticizing Chemical Admixtures.

3. Nanoment L25-HP - New Generation Superplasticizing Chemical Admixtures.

4. Nano Aer - Air Entraining Chemical Admixture.

\subsection{Superplasticizers}

Development of superplasticizers has made a considerable reform in concrete field and the combined use of superplasticizers with fly ash and silica fume has formed a new class of "High Performance Concrete" which is mostly used with conventional concrete [12]. With appropriate dosage use of superplasticizers in RCC water reduction of $12 \%$ can be achieved and $40 \%$ of increase in compressive strength will be gained by first day and flexural strength will be increased by $10 \%$ in 3 days.

\subsection{Air Entraining Agents}

As mentioned after the accidental discovery of air entraining agents, it was the first and original chemical admixture to be used in RCC mixtures and it's the most widely used chemical admixtures nowadays. The functions of this chemical admixture are to increase freeze-thaw durability of concrete and it has lower permeable and absorptivity and in some cases, it can possibly increases the resistance of concrete against the effects of sulfate and alkali 
attacks [13].

\subsection{RCC Mixture Proportioning}

As we mentioned the selection of RCC materials, and the chemical admixtures and the correct proportioning of the materials are very important to produce a good quality RCC mixture [14]. Dosages used for this study is given in table 1 .
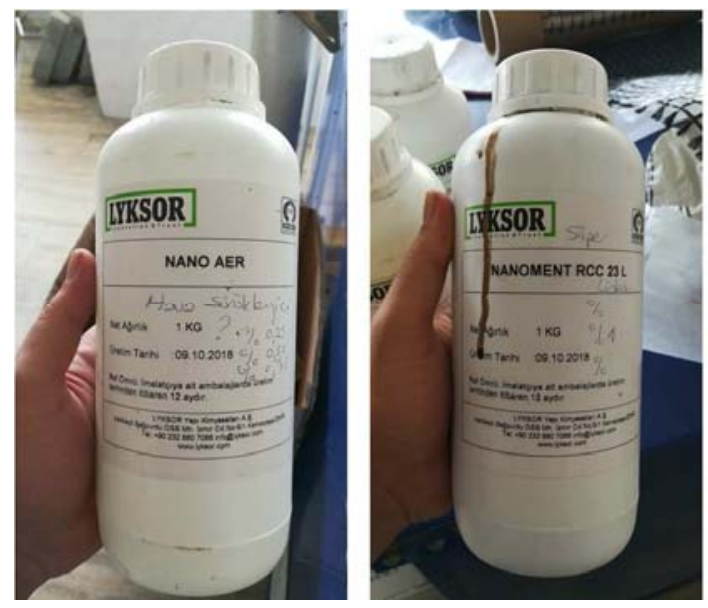

Figure 1. Admixtures used for testing.

\section{Method and Laboratory Studies}

Here in this section we briefly describe the materials, and the standard testing methods used in this work. The test methods we used for determining flexural and compressive strengths are:

1. ASTM C78, Standard Test Method for Flexural Strength of Concrete (Using Simple Beam with ThirdPoint Loading) [15].

2. ASTM C39 / C39M, Standard Test Method for Compressive Strength of Cubic Concrete Specimens [15].

There are so many companies produce chemical admixtures for concrete and chemical admixtures are mostly use with conventional concrete. There is no any company inside turkey other than "Lyxor" to produce chemical admixtures for roller compacted concrete, and the chemical admixtures we have used for this work are specially designed for RCC. Mainly 2 types of admixture are used in this experiment which are consist of 3 different types of Super Plasticizers and Air Entraining agent admixture were selected with different dosages. The reason why we have used the dosages which are shown in table 1 for this study is to gain better compressive and flexural strengths without affecting or reducing the slump ratio and workability of RCC.

\section{Test Method}

First of all, we started with weighting materials like coarse and fine aggregates, cementitious materials, water and admixtures according to the mentioned admixture dosages and adding them into the mixture machine to prepare the RCC concrete mixture. For the compaction of casted $(40 \mathrm{~cm} \times 10 \mathrm{~cm} \times 10 \mathrm{~cm})$ beams a vibrating hammer was used and the concrete was compacted in three different and equal
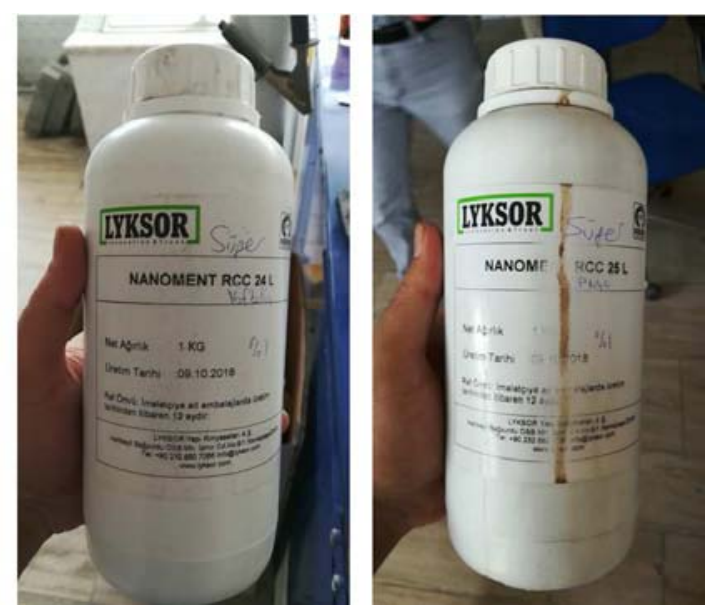

Table 1. Admixture dosages.

\begin{tabular}{lllll}
\hline No & Admixture code & Dosages & & \\
\hline 1 & Nanoment L24-SP & $0.70 \%$ & $1 \%$ & $1.30 \%$ \\
2 & Nanoment L23-MR & $0.70 \%$ & $1 \%$ & $1.30 \%$ \\
3 & Nanoment L25-HP & $0.70 \%$ & $1 \%$ & $1.30 \%$ \\
4 & Nano Aer & $0.70 \%$ & $1 \%$ & $1.30 \%$ \\
5 & None Admix. & $0 \%$ & $0 \%$ & $0 \%$ \\
\hline
\end{tabular}

lifts, and we have prepared a total of 156 samples which includes 12 samples for each admixture with different dosages. As shown in the (figure 9) a 3-point loading machine which was programmed to a data logger to record the shearing loads was used to load on and measure the flexural strength of RCC samples. The flexural and compressive strengths were measured at $3 \mathrm{rd}$, and 28 th day.

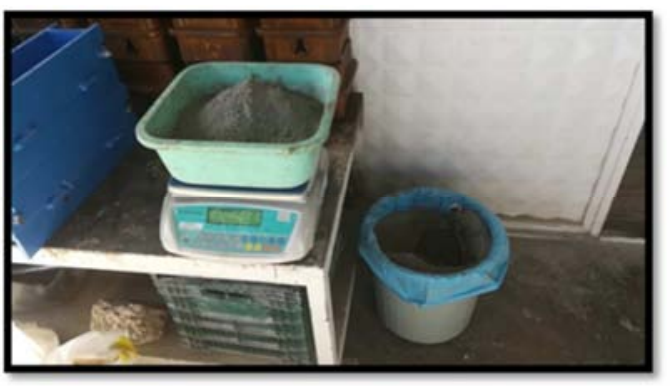

Figure 2. RCC Materiels weighting.

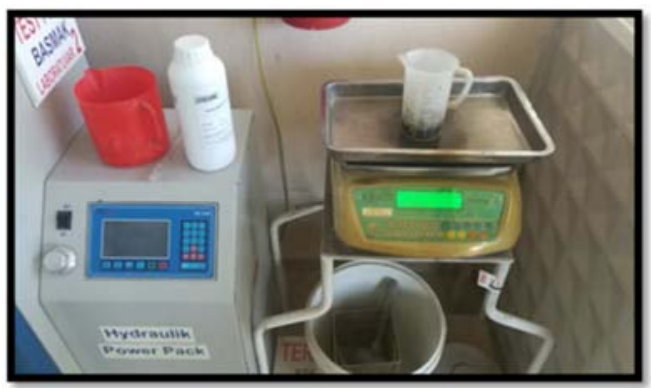

Figure 3. RCC Materiels weighting. 


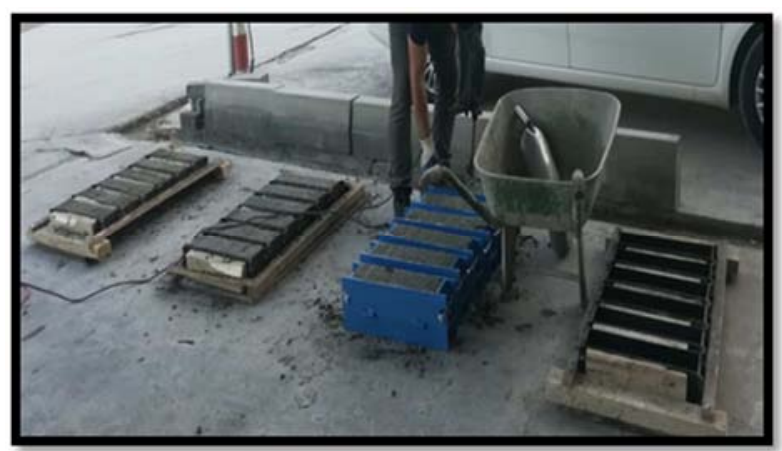

Figure 4. RCC Sample pouring and compaction.

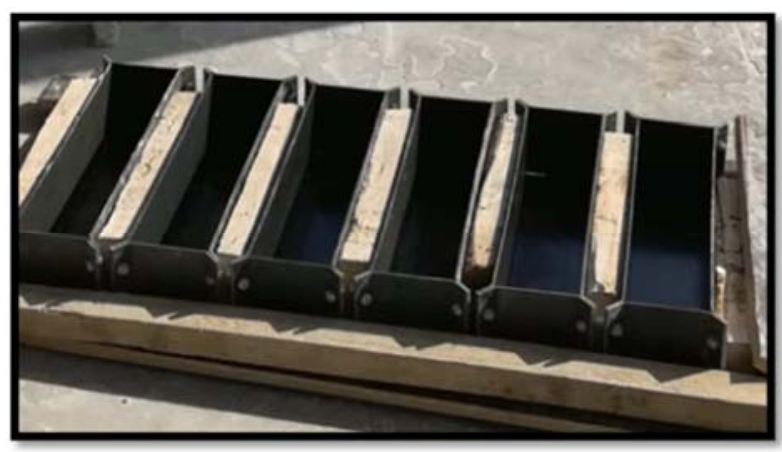

Figure 5. RCC Sample formworks.

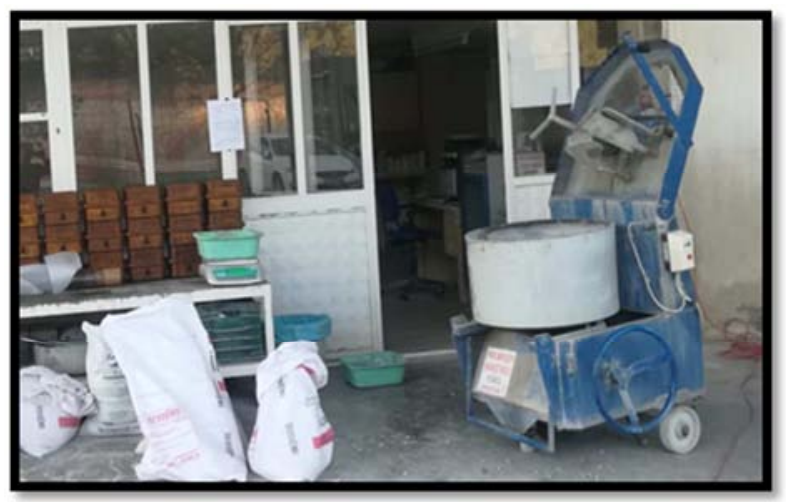

Figure 6. RCC Materiels mixing

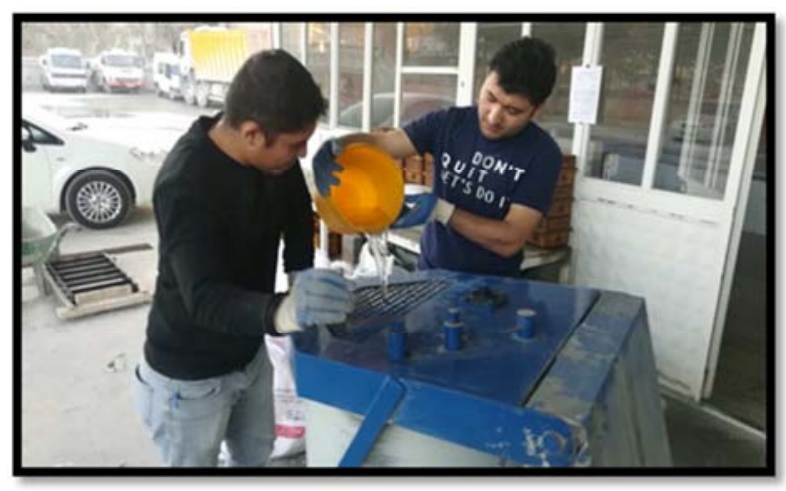

Figure 7. RCC Materiels mixing.

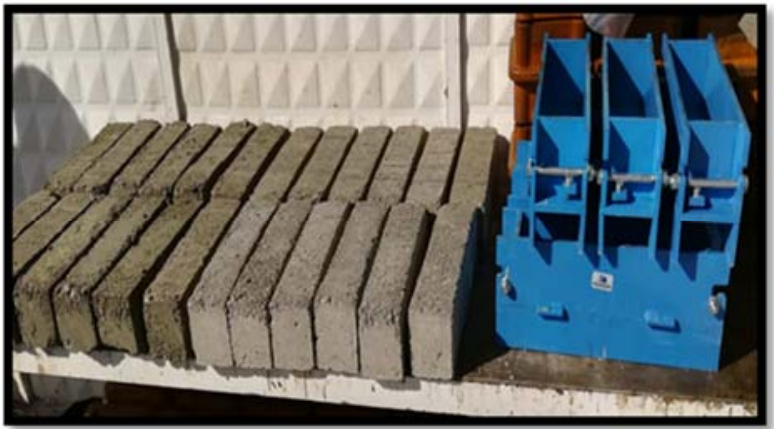

Figure 8. RCC Samples.

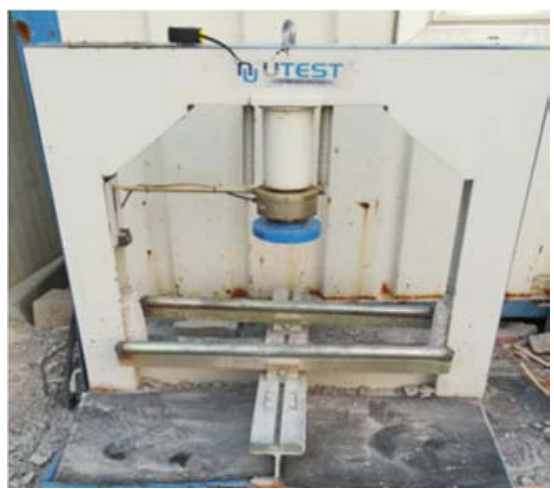

Figure 9. 3 point loading machine.

\section{Result and Suggestions}

Table 2. RCC Test results.

\begin{tabular}{|c|c|c|c|c|c|c|c|c|c|c|c|c|c|c|c|c|c|}
\hline & & \multicolumn{4}{|c|}{3 days compressive strength } & \multicolumn{4}{|c|}{3 days flexural strength } & \multicolumn{4}{|c|}{28 days compressive strength } & \multicolumn{4}{|c|}{28 days flexural strength } \\
\hline & & 1 & 2 & 3 & average & 1 & 2 & 3 & average & 1 & 2 & 3 & average & 1 & 2 & 3 & average \\
\hline \multicolumn{2}{|c|}{ Non-admixed samples } & 6.5 & 6.9 & 6.5 & 6.6 & 26.0 & 27.6 & 26.7 & 26.8 & 8.6 & 8.3 & 8.4 & 8.4 & 34.3 & 33.3 & 34.5 & 34.0 \\
\hline L23 & $0.7 \%$ & 7.2 & 7.3 & 7.4 & 7.3 & 28.9 & 29.2 & 30.2 & 29.4 & 9.4 & 9.3 & 9.4 & 9.3 & 37.6 & 37.0 & 38.5 & 37.7 \\
\hline L23 & $1.0 \%$ & 6.3 & 6.8 & 6.6 & 6.6 & 26.5 & 27.2 & 26.9 & 26.9 & 8.0 & 7.4 & 9.7 & 8.4 & 33.6 & 29.6 & 39.5 & 34.2 \\
\hline L23 & $1.3 \%$ & 6.8 & 7.4 & 7.9 & 7.4 & 28.6 & 29.6 & 32.2 & 30.1 & 8.9 & 8.1 & 7.5 & 8.2 & 37.5 & 32.4 & 30.5 & 33.5 \\
\hline air agent & $0.7 \%$ & 6.9 & 6.6 & 6.2 & 6.6 & 29.0 & 26.4 & 26.0 & 27.1 & 7.5 & 7.7 & 7.6 & 7.6 & 31.4 & 31.0 & 31.8 & 31.4 \\
\hline air agent & $1.0 \%$ & 6.2 & 5.9 & 5.4 & 5.8 & 26.7 & 23.6 & 22.1 & 24.1 & 7.6 & 7.2 & 6.7 & 7.2 & 32.5 & 28.9 & 27.6 & 29.7 \\
\hline air agent & $1.3 \%$ & 5.7 & 7.2 & 6.6 & 6.5 & 24.5 & 28.8 & 27.1 & 26.8 & 7.5 & 7.4 & 6.6 & 7.1 & 32.2 & 29.6 & 26.9 & 29.5 \\
\hline L24 & $0.7 \%$ & 7.7 & 7.2 & 7.8 & 7.6 & 33.1 & 28.8 & 32.0 & 31.3 & 6.8 & 6.5 & 7.9 & 7.1 & 29.2 & 25.8 & 32.4 & 29.2 \\
\hline L24 & $1.0 \%$ & 6.9 & 7.3 & 7.2 & 7.1 & 27.6 & 29.9 & 29.7 & 29.1 & 9.0 & 8.1 & 9.0 & 8.7 & 36.0 & 33.1 & 37.1 & 35.4 \\
\hline L24 & $1.3 \%$ & 6.8 & 6.9 & 7.4 & 7.0 & 28.6 & 28.5 & 30.4 & 29.2 & 8.3 & 8.7 & 7.7 & 8.2 & 35.1 & 35.8 & 31.8 & 34.2 \\
\hline L25 & $0.7 \%$ & 6.9 & 6.8 & 7.3 & 7.0 & 28.6 & 28.0 & 29.9 & 28.8 & 8.1 & 8.3 & 8.3 & 8.2 & 33.7 & 34.0 & 34.2 & 33.9 \\
\hline L25 & $1.0 \%$ & 7.0 & 8.3 & 7.0 & 7.4 & 29.0 & 34.2 & 28.7 & 30.6 & 8.5 & 7.6 & 8.0 & 8.0 & 35.2 & 31.2 & 32.8 & 33.0 \\
\hline L25 & $1.3 \%$ & 8.0 & 7.7 & 7.9 & 7.9 & 33.0 & 31.7 & 32.6 & 32.4 & 8.8 & 9.3 & 8.6 & 8.9 & 36.1 & 38.1 & 35.4 & 36.5 \\
\hline
\end{tabular}




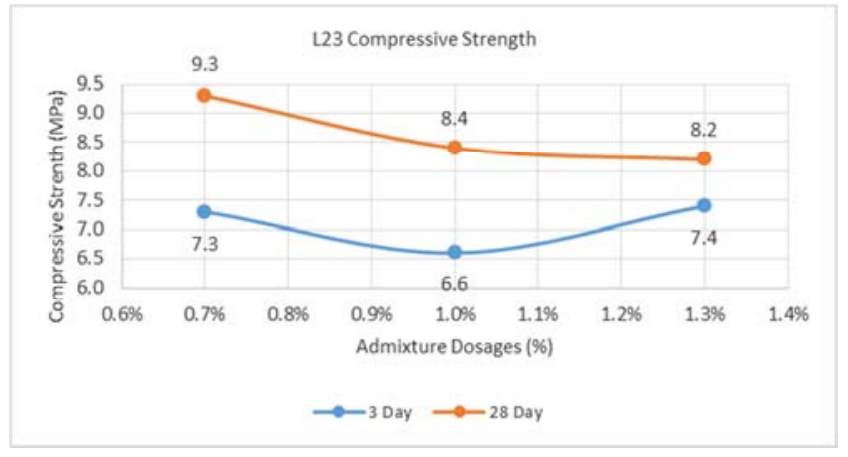

Figure 10. Admixture L23 Compressive strength.

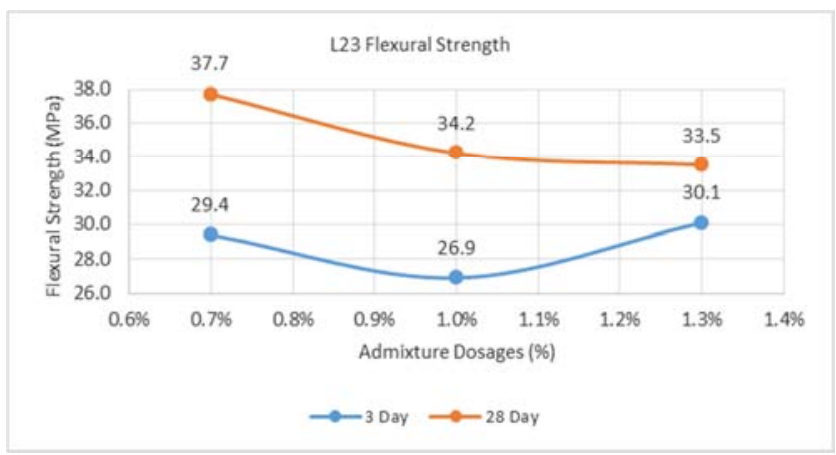

Figure 11. Admixture L23 Flexural strength.

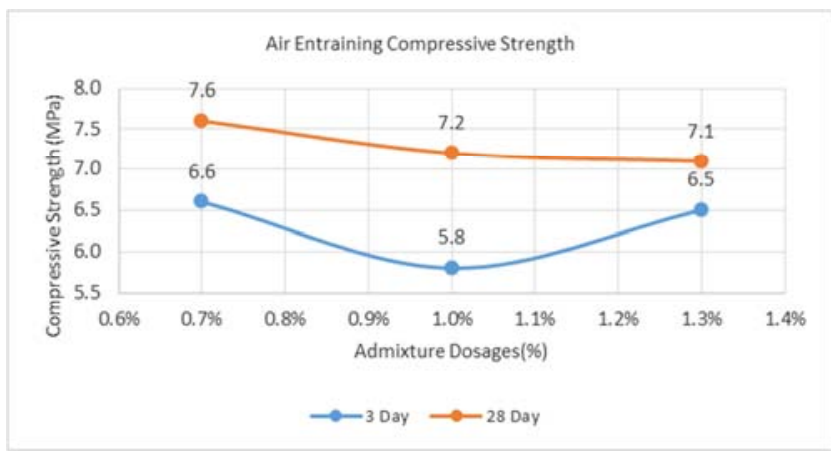

Figure 12. Air Entraining Compressive strength.

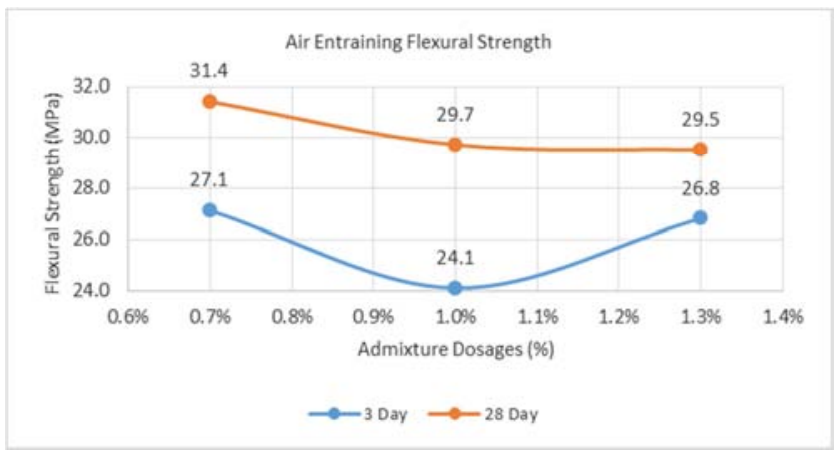

Figure 13. Air Entraining Flexural strength.

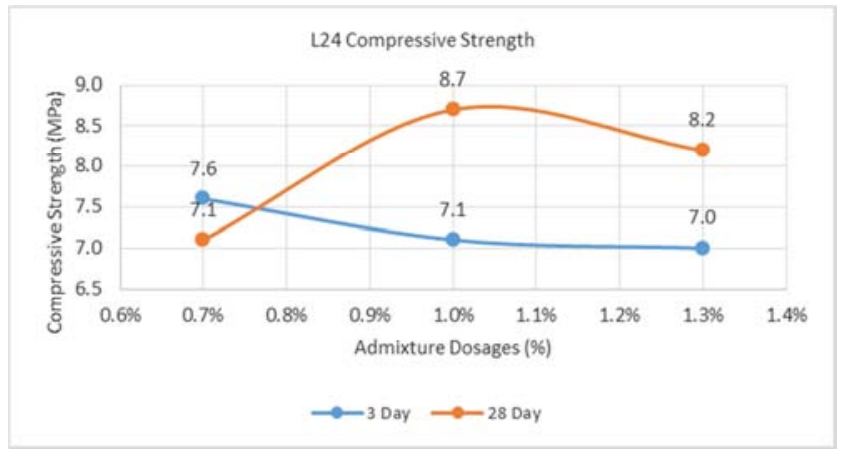

Figure 14. Admixture L24 Compressive strength.

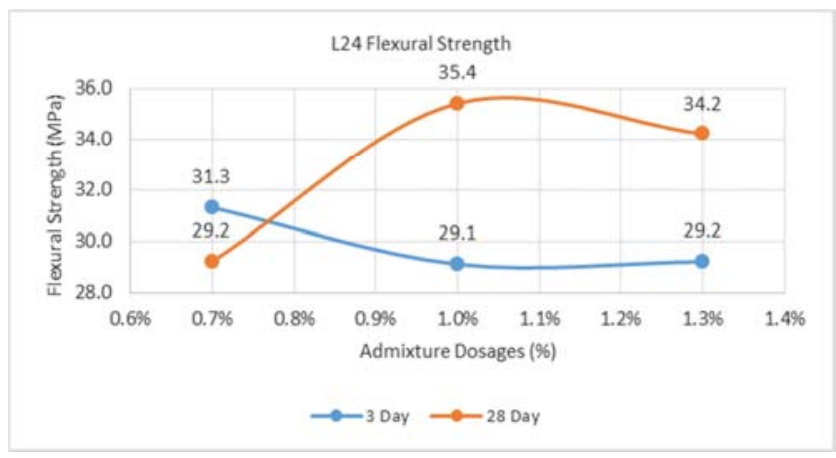

Figure 15. Admixture L24 Flexural strength.

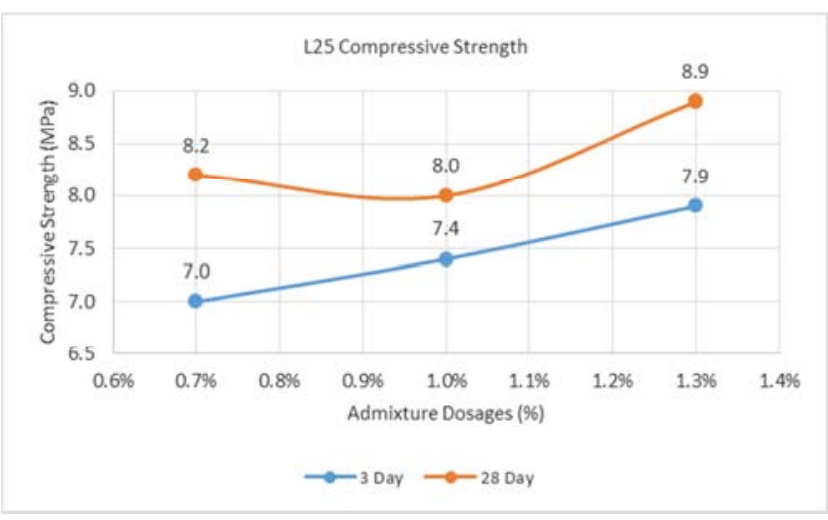

Figure 16. Admixture L25 Compressive strength.

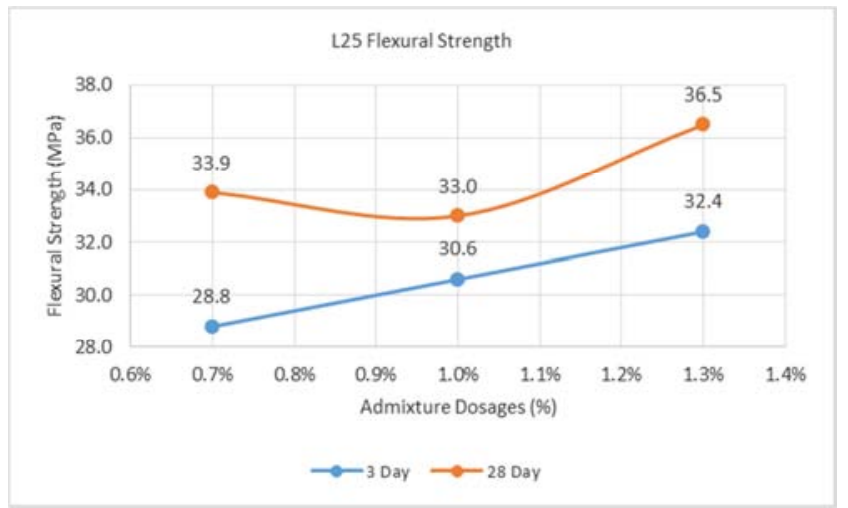

Figure 17. Admixture L25 Flexural strength. 


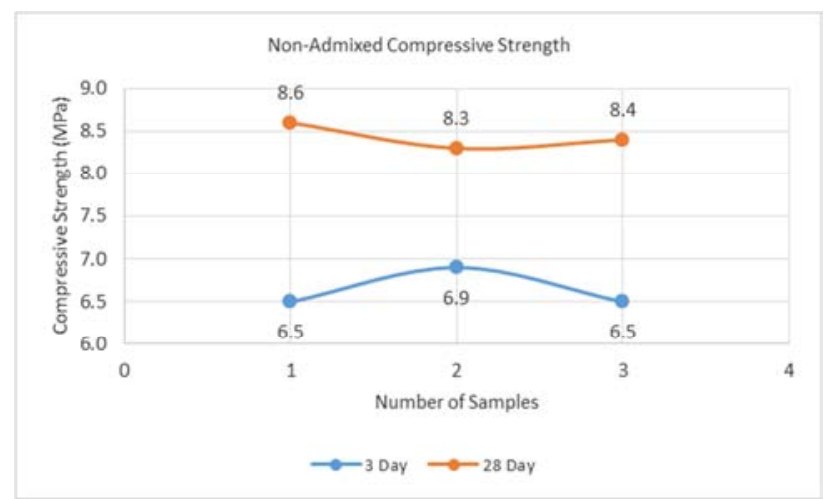

Figure 18. Non-Admixed Samples Compressive strength.

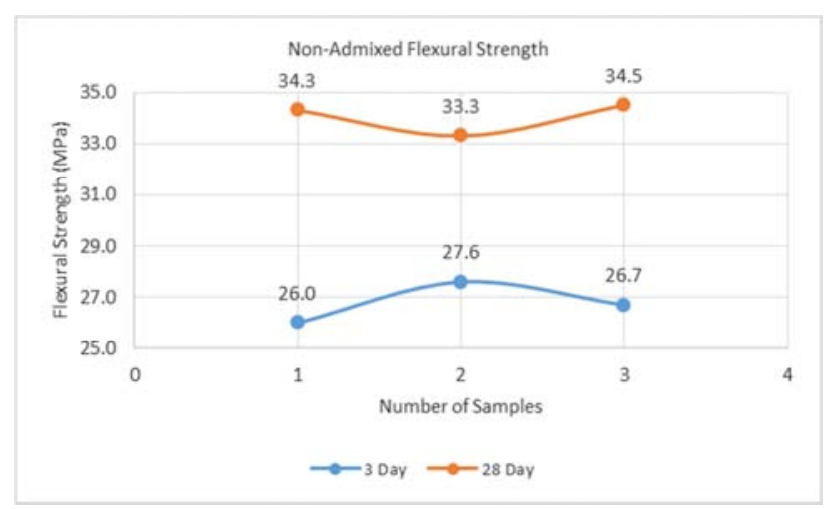

Figure 19. Non-Admixed Samples Flexural strength.

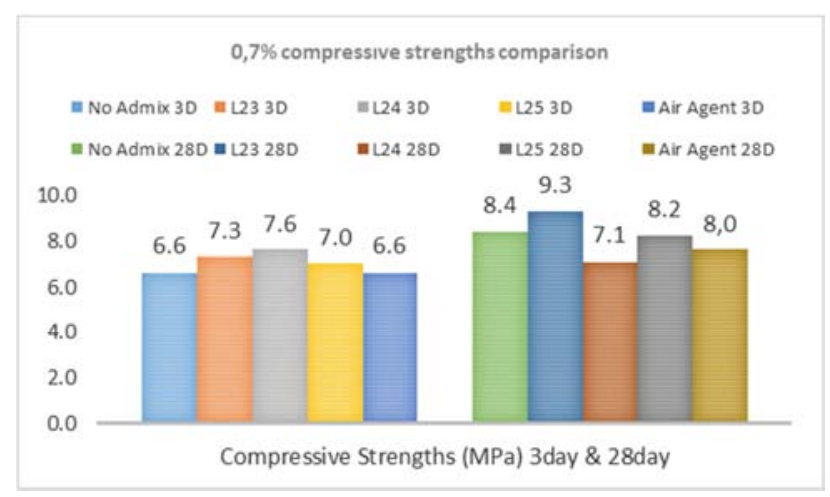

Figure 20. Compressive strength comparison with $0.7 \%$ admixture.

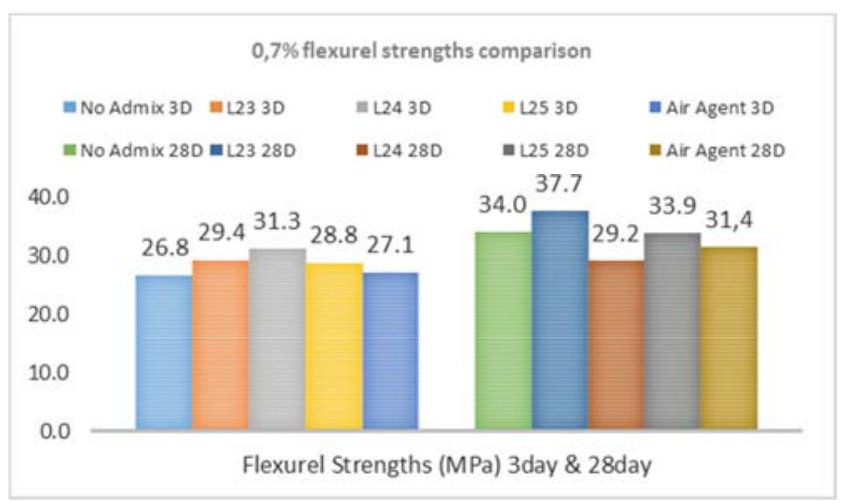

Figure 21. Flexural strength comparison with $0.7 \%$ admixture.

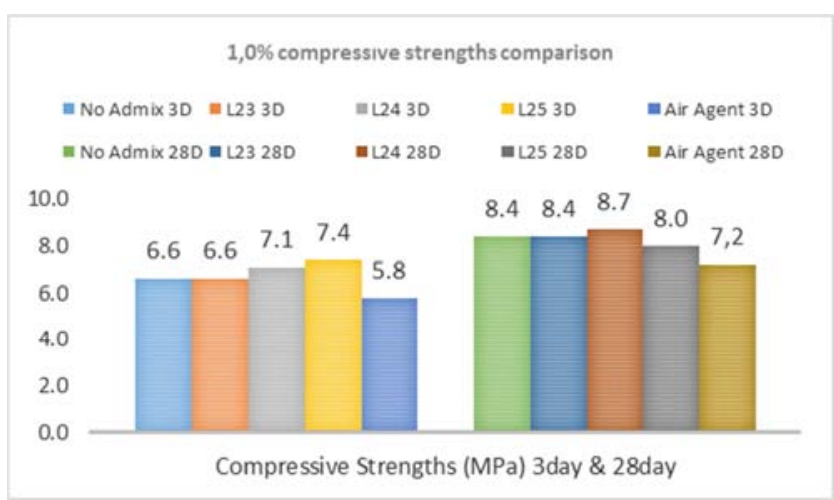

Figure 22. Compressive strength comparison with 1.0\% admixture.

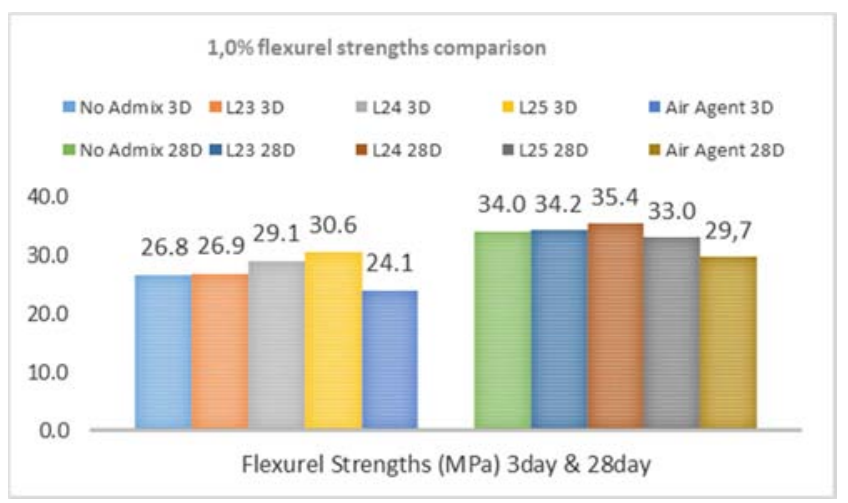

Figure 23. Flexural strength comparison with $1.0 \%$ admixture.

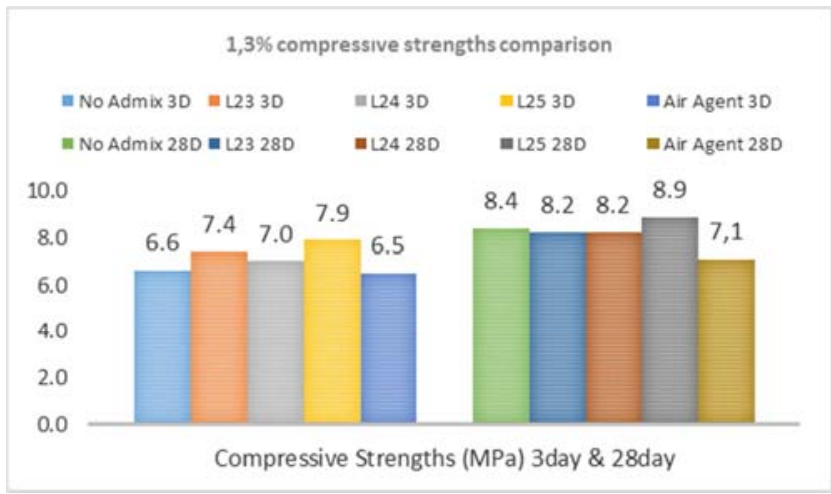

Figure 24. Compressive strength comparison with $1.3 \%$ admixture.

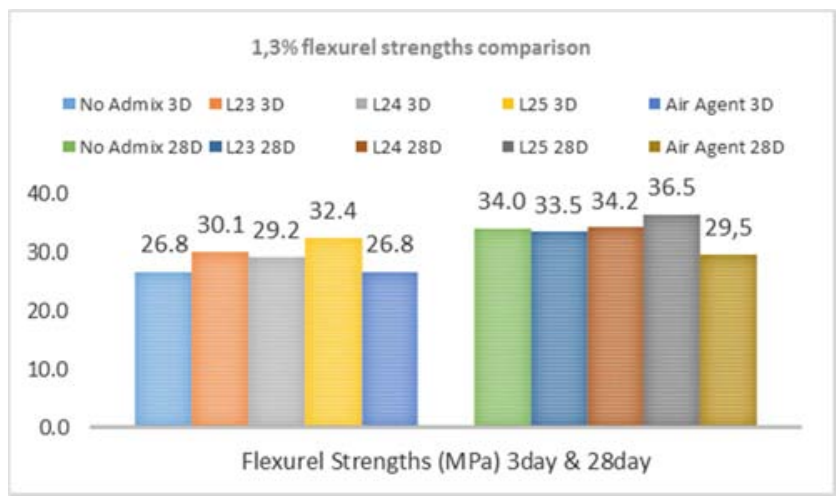

Figure 25. Flexural strength comparison with 1.3\% admixture. 
According to the results from the tests we performed, comparing these results with non-admixed rcc samples, we can mention several important issues, including: Considering the comparison of the experimental results of the RCC samples with $0.7 \%$ admixed ratio with the experimental results of the pure RCC samples, the mean of the compressive strengths is as follows: L23 chemical admixture samples increased by $9.60 \%$ for 3 days and increased $9.70 \%$ for 28 days. Increase of $13.20 \%$ for 3 days in L24 chemical admixture samples and $18.86 \%$ decrease for 28 days. Increase of $6.82 \%$ for 3 days in L25 chemical admixture samples, it was observed that there was a decrease of $2.40 \%$ for the 28 days, there was no change for 3 days in air entrained admixture samples and there was a $5.00 \%$ decrease for 28 days. The average flexural strength of $0.7 \%$ chemical admixture is as follows: In L23 chemical admixture samples, there was an increase of $8.90 \%$ for 3 days and a $9.90 \%$ increase for 28 days, the increase of $14.40 \%$ for 3 days in L24 chemical admixture samples and the decrease of $13.60 \%$ for 28 days, the increase of $7.00 \%$ for 3 days in L 25 chemical admixture samples and It was observed that there was an increase of $0.80 \%$ for 28 days, $7.80 \%$ decrease for 28 days for air-entraining admixture samples and increase of $1.20 \%$ for 3 days.

Considering the comparison of the experimental results of RCC samples with $1.0 \%$ admixture ratio with the experimental results of the non-admixed RCC samples, the mean of the compressive strengths: L23 admixture samples had no change for 3 and 28 days, there was $7.10 \%$ increase for 3 days in L24 admixture samples, there was $3.50 \%$ increase for 28 days. It was observed that there was a decrease of $12.30 \%$ for 3 days in air-entrained samples with a decrease of $13.40 \%$ for 28 days. The average flexural strength of $1.0 \%$ chemical admixture is as follows: L23 admixture samples showed an increase of $0.40 \%$ for 3 days, an increase of $0.10 \%$ for 28 days, increase of $8.00 \%$ for 3 days in L24 admixture samples, an increase of $4.00 \%$ for 28 days, increase of $12.50 \%$ for 3 days in L25 admixture samples, It was observed that there was a decrease of $3.00 \%$ for the 28 day, there was a decrease of $10 \%$ for 3 days in air entrained admixture samples, a decrease of $14.00 \%$ for 28 days.

Considering the comparison of the experimental results of the RCC samples with $1.3 \%$ chemical admixture ratio with the experimental results of the pure RCC samples, the mean of the compressive strengths: In L23 admixture samples, there was an increase of $10.90 \%$ for 3 days, $1.60 \%$ decrease for 28 days, increase of $5.80 \%$ for 3 days in L24 admixture samples, $1.60 \%$ decrease for 28 days, increase of $6.50 \%$ for 3 days in L25 admixture samples and It was observed that there was a decrease of $5.70 \%$ for 28 -day decrease in air-entrained admixture samples with a decrease of $5.70 \%$ for the 28 day. The average flexural strength of $1.3 \%$ chemical admixture is as follows: L23 admixture samples had an increase of $11.00 \%$ for 3 days, $1.60 \%$ decrease for 28 days, increase of $8.30 \%$ for 3 days in L24 admixture samples, increase of $0.60 \%$ for 28 days, increase of $17.30 \%$ for 3 days in L25 admixture samples, It was observed that there was an increase of $8.90 \%$ for the 28 day, there was no change for 3 days for air entrained admixture samples and a decrease of $15.20 \%$ for 28 days.

The result of three-day: relatively good results of the use of chemical admixture L25-HP or (New generation Superplasticizers) in RCC. Using a dosage $1.3 \%$ of this material in RCC, a better compressive strength and flexural strength than non-Admixture RCC was obtained from a three-day result, which illustrates the good effect of these materials on application in concrete constructions that are necessary for early use.

\section{$7.9 \mathrm{mpa}>6.6 \mathrm{mpa}$ (flexural strength) $32.4 \mathrm{mpa}>26.8 \mathrm{mpa}$ (compressive strength)}

And if we look at the results of 28-day of this study, it can be seen that by using $0.7 \%$ of the chemical admixture L23MR (Midrange Water Reducer) can be obtained a higher result of the Flexural and compressive strength than other admixtures and non-admixture samples. $9.3 \mathrm{mpa}>8.4 \mathrm{mpa}$ (flexural strength) $37.7 \mathrm{mpa}>34 \mathrm{mpa}$ (compressive strength)

In case of examining the results of all the chemical admixtures used in this study, a general conclusion can be made considering its compressive and flexural strengths and also its economic factors. The results of this study show that by using the lowest amount of $0.7 \%$ of the chemical admixture L23-MR, can be obtained higher flexural and compressive strength than other chemical admixtures and none admixed concrete for short- and long-term use. Considering its economic factors, the price of this chemical admixture which is lower than other chemical admixtures, and the dosage we can recommend for the higher strengths is $0.7 \%$, which can be said to be 7 liters of this chemical admixture in $1 \mathrm{~m}^{3}$ of RCC.

\section{Conclusion}

The selection of chemical admixtures to use for transportation related structures by evaluating its technical and economic factors has always been very important. Sometimes it depends on its effectiveness and qualification, sometimes depends on the technical specification of the project, sometimes depends on the desired performance and sometimes depends on the weather or environmental conditions, arranging the dosage use of selected chemical admixture according to mixture proportion of RCC. Using appropriate dosage of air entraining agent to increase durability of concrete against freezing and thawing conditions is clearly important but it's also important to gain a greater compressive and flexural strengths in RCC by using one specific admixture (as we tested and gain a better flexural and compressive strength by using superplasticizers). Sometimes using several different chemical admixtures without evaluating its dosages and qualification may cause 
problems and could be inappropriate mixing them with RCC at the same time and it should carefully be designed and evaluated. Most of the time chemical admixtures can be used individually according to their specifications and sometimes the combined use of different chemical admixtures could be useful if correctly designed and carefully proportioned.

\section{Acknowledgements}

I would like to take this opportunity and thank Prof. Dr. Soner HALDENBILEN for all his help, sharing his knowledge and experience and all my other friends and family for all their support in period of completion of this excremental work.

\section{References}

[1] Wikipedia. (2020). Transport. Retrieved from https://en.wikipedia.org/wiki/Transport.

[2] Longfellow, R. (2017, 06 27). Highway History. Retrieved from U.S. Department of Transportation, Federal highway transportation:

https://www.fhwa.dot.gov/infrastructure/back0506.cfm.

[3] American Concrete Pavement Association. (2017, June 23). George Bartholomew Event to Celebrate First Concrete Pavement. Retrieved from https://www.acpa.org/tag/georgebartholomew/.

[4] Sidney Diamond, K. M. (1992). Chemical Admixtures for Highway Concrete: Fundamental Research and a Guide to Usage. Indiana: Indiana Department of Transportation and U.S. Department of transportation federal highway administration.

[5] Hazaree, C. V., Ceylan, H., Taylor, P., Gopalakrishnan, K., Wang, K., \& Bektas, F. (2013). Use of Chemical Admixtures in Roller Compacted Concrete for Pavements. National Concrete Pavement Technology Center.

[6] Y. Mohan Sai Kiran, S. K. (2015). Effect fo Mineral Admixture on Strength Properties of Roller Compacted Concrete. International Journal of Scientific Research.

[7] Edel Cortez, L. B. (2010). Cold Roller Compacted Concrete for Roads and Hardstands on Army Installation in Cold Regions. Hanover: U.S. Army Engineer Research and Development Center Cold Regions Research and Engineering Laboratory.
[8] Cenk Karakurt, R. P. (2015). Properties of Roller Compacted Concretes Produced with Fly Ash and Ground Granulated Blast Furnace Slag. Bilecik: Bilecik Şeyh Edebali Üniversitesi Fen Bilimleri Dergisi.

[9] Shayma Al Baghdady, L. K. (2018). Designing Roller compacted concrete (RCC) dams. Stockholm: Royal Institute of Technology (KTH).

[10] Fabrizio Avallone, M. J. (2019). Concrete Sika RCC Dams Handbook. Zürich: Sika AG.

[11] Anitha Jayan, P. S. (2016). Influence of Admixtures on Behavior of Concrete. International Journal of Research in Advent Technology.

[12] Kosmatka Steven, K. B. (2002). Design and Control of Concrete Mixtures (Chapter 17). Research Gate.

[13] Pierre Claude Aïtcin, R. J. (2015). Science and technology of concrete admixtures (Chapter 17). Research Gate.

[14] Nemati, K. (2015). University of Washington. Retrieved from Concrete Technology, Mix-Proportioning: courses.washington.edu.

[15] ASTM International. (2007). Standards and Publications. Retrieved from http://www.astm.org/cgi-bin/resolver.cgi?C7807.

\section{Biography}

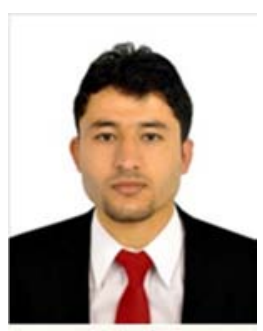

Mohammad Arif Nero: He received his bachelor's degree from Blkh university of Afghanistan in 2012. Recently completed his MSc in Pamukkale university of Denizli/Turkey.

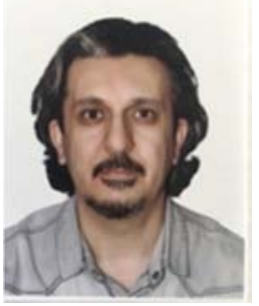

Soner Haldenbilen: In 1992 he completed his civil engineer education. He received his $\mathrm{PhD}$ degree from Pamukkale University of Denizli/Turkey in 2003. He has been working as a professor in the Department of Transportation at the Faculty of Engineering of Pamukkale University. 